\title{
Transcriptomic response of Anopheles gambiae sensu stricto mosquito larvae to Curry tree (Murraya koenigii) phytochemicals
}

\author{
Clarence M. Mang'era ${ }^{1,2^{*}}$, Fathiya M. Khamis ${ }^{3}$, Erick O. Awuoche ${ }^{4}$, Ahmed Hassanali ${ }^{5}$, \\ Fidelis Levi Odhiambo Ombura ${ }^{3}$ and Paul O. Mireji $i^{*}$ (D)
}

\begin{abstract}
Background: Insect growth regulators (IGRs) can control insect vector populations by disrupting growth and development in juvenile stages of the vectors. We previously identified and described the curry tree (Murraya koenigii (L.) Spreng) phytochemical leaf extract composition (neplanocin A, 3-(1-naphthyl)-L-alanine, lumiflavine, terezine C, agelaspongin and murrayazolinol), which disrupted growth and development in Anopheles gambiae sensu stricto mosquito larvae by inducing morphogenetic abnormalities, reducing locomotion and delaying pupation in the mosquito. Here, we attempted to establish the transcriptional process in the larvae that underpins these phenotypes in the mosquito.
\end{abstract}

Methods: We first exposed third-fourth instar larvae of the mosquito to the leaf extract and consequently the inherent phytochemicals (and corresponding non-exposed controls) in two independent biological replicates. We collected the larvae for our experiments sampled $24 \mathrm{~h}$ before peak pupation, which was 7 and 18 days post-exposure for controls and exposed larvae, respectively. The differences in duration to peak pupation were due to extract-induced growth delay in the larvae. The two study groups (exposed vs control) were consequently not age-matched. We then sequentially (i) isolated RNA (whole larvae) from each replicate treatment, (ii) sequenced the RNA on Illumina HiSeq platform, (iii) performed differential bioinformatics analyses between libraries (exposed vs control) and (iv) independently validated the transcriptome expression profiles through RT-qPCR.

Results: Our analyses revealed significant induction of transcripts predominantly associated with hard cuticular proteins, juvenile hormone esterases, immunity and detoxification in the larvae samples exposed to the extract relative to the non-exposed control samples. Our analysis also revealed alteration of pathways functionally associated with putrescine metabolism and structural constituents of the cuticle in the extract-exposed larvae relative to the non-exposed control, putatively linked to the exoskeleton and immune response in the larvae. The extract-exposed larvae also appeared to have suppressed pathways functionally associated with molting, cell division and growth in the larvae. However, given the age mismatch between the extract-exposed and non-exposed larvae, we can attribute the modulation of innate immune, detoxification, cuticular and associated transcripts and pathways we observed to effects of age differences among the larvae samples (exposed vs control) and to exposures of the larvae to the extract.

\footnotetext{
*Correspondence: cmmangera@gmail.com; mireji.paul@gmail.com

1 Department of Biochemistry and Molecular Biology, Egerton University,

Njoro Campus, PO Box 536-20115, Egerton, Kenya

${ }^{6}$ Biotechnology Research Institute-Kenya Agricultural and Livestock

Research Organization, PO Box 362-00902, Kikuyu, Kenya

Full list of author information is available at the end of the article
}

(c) The Author(s) 2021. Open Access This article is licensed under a Creative Commons Attribution 4.0 International License, which permits use, sharing, adaptation, distribution and reproduction in any medium or format, as long as you give appropriate credit to the original author(s) and the source, provide a link to the Creative Commons licence, and indicate if changes were made. The images or other third party material in this article are included in the article's Creative Commons licence, unless indicated otherwise in a credit line to the material. If material is not included in the article's Creative Commons licence and your intended use is not permitted by statutory regulation or exceeds the permitted use, you will need to obtain permission directly from the copyright holder. To view a copy of this licence, visit http://creativecommons.org/licenses/by/4.0/. The Creative Commons Public Domain Dedication waiver (http://creativeco mmons.org/publicdomain/zero/1.0/) applies to the data made available in this article, unless otherwise stated in a credit line to the data. 
Conclusions: The exposure treatment appears to disrupt cuticular development, immune response and oxidative stress pathways in Anopheles gambiae s.s larvae. These pathways can potentially be targeted in development of more efficacious curry tree phytochemical-based IGRs against An. gambiae s.s mosquito larvae.

Keywords: Anopheles gambiae s.s, Growth disruption, Mosquito larvae, Differential gene expression, Murraya koenigii

\section{Background}

Anopheles gambiae s.s is a vector of human malaria disease responsible for $>400,000$ deaths worldwide, mostly (> 93\%) in sub-Sahara Africa [1]. Most control strategies against An. gambiae target the adult stage of the vector [2] and rely on pyrethroids, organochlorides, organophosphates and carbamates among other insecticides and against which the vector has developed resistance [3]. The resistance has adversely affected integrated mosquito vector control strategies [4] and necessitated a search for alternative control agents, including phytochemicals, that target immature stages of the vector [5]. This approach has largely been unexplored [6, 7]. Targeting the immature stages can perturb mosquito population dynamics, consequently contributing to reduced vectorial capacity and local malaria transmission [8]. However, this approach requires environmentally friendly agents because of the aquatic nature of mosquito larval habitats typically shared with many non-target organisms that include humans, livestock and crops. The phytochemicals provide better candidates for new classes of insecticides because they (i) consist of variable components with diverse mechanisms of action that diminish the odds of development of resistance in the mosquito to the phytochemicals [9], (ii) generally have minimal acute toxicity to vertebrates and (iii) are environmentally safe [10]. Current effective phytochemical agents targeting developmental stages in An. gambiae include larvae and/or pupae growth inhibitors [11, 12], larvicides [13] and ovicides [14]. These phytochemicals were derived from various mahogany (Meliaceae) plant families [15, 16], Japanese cedar (Cryptomeria japonica) [17], black pepper (Piper nigrum) [18], Indian wild pepper (Vitex trifolia) [19] and wild honeysuckle tree [20]. We recently assessed the effects of exposure of larval stages of $A n$. gambiae sensu stricto to sub-lethal doses of leaf extracts from the curry tree (Murraya koenigii) and described the phytochemical composition of the extract [11]. We established that the exposure induced gross morphogenic abnormalities in the larvae and emergent adults, reduced larval locomotion and delayed pupation in the mosquito. We further established that the leaf extract was a blend of at least neplanocin A, 3-(1-naphthyl)-L-alanine, lumiflavine, terezine $C$, agelaspongin and murrayazolinol alkaloid phytochemicals [11].
We, therefore, undertook the present study to establish the molecular process that putatively underpins the phenotypes above that were observed in the An. gambiae s.s larvae following the exposure to the sub-lethal doses of phytochemical leaf extracts from the curry tree. However, the effect of delayed pupation on larvae by the extract [11] suggested a differential rate of growth between extract-exposed and non-exposed larvae, presenting unique challenges in age-matching larvae from the two populations. Consequently, larvae of chronologically similar age are potentially physiologically different (at different larval instar developmental stages) because of the differential growth rates between the populations. Second, such toxicity assessments are typically performed on $\mathrm{L}_{3} / \mathrm{L}_{4}$ instar larvae (irrespective of numerical age of the larvae) since growth inhibition compounds have the most profound effect on insects at that metamorphosis stage of their growth [21]. Faced with this challenge, we selected $24 \mathrm{~h}$ preceeding peak pupation $\left(\mathrm{L}_{3} / \mathrm{L}_{4}\right.$ instar larvae) in both populations as the appropriate sampling point that were potentially physiologically similar but of dissimilar age. The consequence of this approach is that our findings reflect responses to an inevitable combination of age differences between the larval populations and the xenobiotic (extract) challenge. We identified potential molecular target candidates that can aid in research and development of more efficacious IGRs against An. gambiae s.s mosquito larvae.

\section{Methods \\ Preparation of An. gambiae s.s larvae biological samples for RNA isolation}

We obtained An. gambiae s.s mosquito larvae from a mosquito colony maintained at the International Centre of Insect Physiology and Ecology (ICIPE), Nairobi, Kenya. This mosquito colony was originally initiated, reared and maintained at Mbita Point Research and Training Centre of ICIPE, Homa Bay County, Kenya, from adults collected in 1996 at Njagi village in south-east Tanzania [22]. The colony was transferred and used to establish the An. gambiae s.s colony we used for our study at ICIPE, Nairobi, Kenya, in December 2000. This colony had never been previously exposed to any insecticide or growthregulating xenobiotics, including plant extracts, and was thus considered susceptible to known insecticides and other xenobiotics. We followed standard procedures for 
rearing Anopheles mosquitoes [23]. We reared all life stages in an insectary $\left(28 \pm 2{ }^{\circ} \mathrm{C}, 75-80 \%\right.$ relative humidity) at the Animal Rearing and Quarantine Unit of ICIPE, Nairobi, Kenya. From the day of emergence, we provided adult mosquitoes with a $10 \%$ sugar solution soaked in cotton wool. We fed 3-day-old adult female mosquitoes on bovine blood using an artificial membrane feeding method [24]. Approximately 2-3 days later, we placed oviposition dishes in the cage containing gravid females. We placed the eggs on water and surrounded them with floating wax paper to prevent them from getting stranded on the sides of the hatching tray. We typically placed about $30 \mathrm{mg}$ pulverized Tetramin fish food (Tetra GmbH, Melle, Germany) per pan of water twice daily (three times daily after reaching the third larval stage). We collected the pupae daily, transferred them to bowls with water and placed the bowls in cages for adult emergence. For our study, we maintained the larvae on $0.3 \mathrm{mg}$ powdered Tetramin fish meal per larvae per day as recommended for An. gambiae s.s larvae [25] under the insectary conditions. This quantity of food was sufficient to sustain the larvae for $24 \mathrm{~h}$ while establishing minimal residual food that could potentially interfere with bioavailability of the extract to the larvae.

We exposed the larvae to curry tree leaf extract following the protocol of Mang'era et al. [11] with relevant modifications for our current applications. The extract consisted of a natural blend of alkaloid phytochemicals (neplanocin A, 3-(1-naphthyl)-L-alanine, lumiflavine, terezine $C$, agelaspongin and murrayazolinol) and induced morphogenetic abnormalities, reduced locomotion and delayed pupation (8-day delay) in the larvae [11]. Briefly, we initiated this process by establishing the temporal range of toxicity of specific phytochemical extract concentration $(2 \mathrm{ppm})$ to late third-early fourth instar larvae $\left(\mathrm{L}_{3} / \mathrm{L}_{4}\right)$ of the mosquito. The temporal range was critical to our determination of optimal duration of exposure of the larvae to putatively elicit molecular responses to our extract at the $\mathrm{L}_{4}$ instar larvae just before pupation. We selected this concentration (2 ppm) since we have previously identified it as sub-lethal to the $\mathrm{L}_{3} / \mathrm{L}_{4}$ of the mosquito in an extract toxicity range (median lethal concentration) assessment [11]. For this purpose (establishing the temporal range of toxicity), we first solubilized the extract in absolute ethanol and diluted the resultant solution to $2 \mathrm{ppm}$ in a total volume of $100 \mathrm{ml}$ solution of distilled water (in a $250-\mathrm{ml}$ glass beaker). Our overall ethanol concentration was $0.2 \%(\mathrm{v} / \mathrm{v})$ absolute ethanol in the distilled water, based on the quantity of absolute ethanol we initially used to solubilize the extract. We then placed $20 \mathrm{~L}_{3} / \mathrm{L}_{4}$ instar larvae of the mosquito into the solution, consequently exposing them to the extract and serving as our exposed treatment. We similarly placed $20 \mathrm{~L}_{3} / \mathrm{L}_{4}$ instar larvae in $100 \mathrm{ml}$ of distilled water with a similar concentration of absolute ethanol in a water beaker (in a $250-\mathrm{ml}$ glass beaker) that served as our control treatment. The absolute ethanol concentration equivalence between the treatments potentially assisted in contrasting the effect of the extract from that of the solubilizing agent in downstream analyses. We prepared five replicates each of the treatment and control and monitored daily mortality and pupation of these larvae in both treatments under insectary conditions.

Our findings revealed peak pupation of the larvae 7 and 18 days post-exposure to our control and exposed treatments, respectively (Fig. 1a, b), suggesting that (i) the extract appeared to delay growth in the larvae and, consequently, the exposed and associated control larvae were potentially physiologically $\left(\mathrm{L}_{3} / \mathrm{L}_{4}\right.$ instar larvae) similar 7 and 18 days post-exposure (dpe), respectively. At this point 81 and $53 \%$ of the larvae had pupated or eclosed (Fig. 1a) for control and exposed larvae populations, respectively, indicating that the remaining respective proportions would potentially be appropriate $\mathrm{L}_{4}$ instar larvae for further analyses in the definitive phase of our studies. The significant extension of larval phase (delayed pupation) by the extract exposure presented us with unique challenges in selection of the sampling points for the RNA extraction and subsequent RNASeq experiments. We reckoned that age-matching by sampling the larvae from either population 7 days postexposure (peak pupation in control population) would constitute comparison between $\mathrm{L}_{2}$ exposed and $\mathrm{L}_{3 / 4}$ control larvae populations; hence, the outcome/results would be confounded by differences in the physiological states between the populations. The alternative was to consider exposed and control larvae populations 7 and 18 dpe, respectively, as physiologically equivalent (both at $\mathrm{L}_{3} / \mathrm{L}_{4}$ instar larvae developmental stage). The results from this approach would be confounded by the age differences between the larvae populations. Balancing these options and their consequences, we selected the latter option since growth inhibition compounds typically have the most profound effect on insects at the $\mathrm{L}_{3} / \mathrm{L}_{4}$ instar larval metamorphosis stage (physiologically matched) of their growth [26]. Consequently, our molecular results would reflect responses to the inevitable combination of age differences between the larvae populations and the xenobiotic (extract) challenge. The exposed will hereafter refer to this larvae population (extract-exposed but not age-matched larvae population).

For assessment of molecular events associated with the exposure to the phytochemical extract, we repeated similar treatments (exposed and control), but in 15 independent biological replicates of 25 larvae per treatment, to enhance the odds of obtaining sufficient surviving larvae 

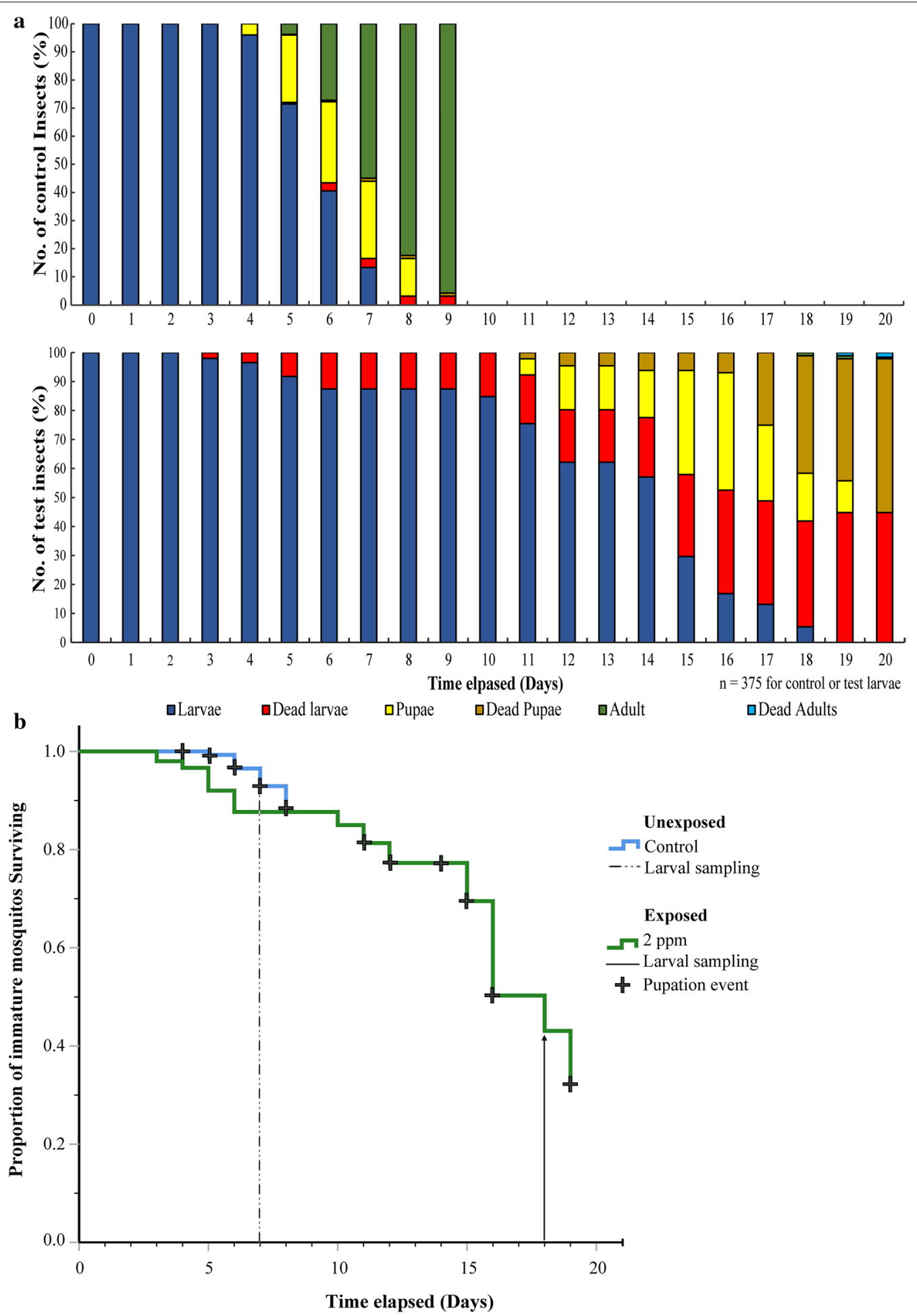

Fig 1 a Bar graph showing daily pupation/mortality ratios for unexposed and exposed $L_{3} / L_{4}$ instar larvae throughout the experiment. $\mathbf{b}$ Kaplan-Meier plot showing survival trends of unexposed and exposed (2 ppm) larvae 
for the subsequent molecular studies, given potential 55\% mortality and $59 \%$ pupation as revealed by our preliminary studies (Fig. 1a) and the need to minimize crowding of the larvae in the beakers. We monitored and recorded larval survivorship at 24-h intervals, indicating numbers of larvae alive, dead or moribund, and removed the dead larvae. Since we were interested in two biological replicates each for the control or exposed treatments for our subsequent RNA-Seq molecular comparative analyses, we randomly and separately assigned five replicates from each treatment (exposed or control) into two groups of five treatments each. We performed these assignments 7 or 18 dpe for the control or exposed treatments, respectively. From the 50 and $49 \mathrm{~L}_{4}$ instar larvae survivors from control and exposed treatments, respectively (Fig. 1b), we pooled surviving larvae in each group into two separate 1.5-ml reaction tubes, constituting our two biological replicates of surviving larvae for subsequent RNA isolations and analyses. The replicates consisted of 25, 25, 25 and 24 larvae in each of control replicates 1 and 2 and exposed replicates 1 and 2, respectively. We quickly centrifuged the larvae in the tubes at 15,300 rcf for $1 \mathrm{~min}$ (Eppendorf AG 5417R centrifuge, Hamburg, Germany) to pellet the larvae and facilitate removal of the residual water. We then snap froze the larval pellet in liquid nitrogen until RNA isolation.

\section{Isolation and sequencing of An. gambiae s.s RNA}

We isolated total An. gambiae s.s RNA from the two biological independent replicates (from control or exposed larvae) by mechanically crushing the larvae using disposable RNAse-free plastic pestles in ISOLATE II RNA Mini Kit buffer (Bioline, Merdian Life Sciences, London, UK) following the manufacturer's protocol. We then treated resultant total RNA with TURBO DNase ${ }^{\mathrm{TM}}$ (Ambion Life Technologies, TX, USA), following the manufacturer's instructions, to remove potentially contaminating DNA that could confound our subsequent RNA-Seq analysis. We verified the quality and integrity of the RNA samples using Agilent Bioanalyzer 2100 (Agilent, Palo Alto, CA, USA) according to the manufacturer's instructions. We sourced services for cDNA library preparation from the total RNA and subsequent sequencing of the libraries from Macrogen, Korea (Geumcheon-gu, Seoul, Republic of Korea). Therein, cDNA libraries were prepared from $900 \mathrm{ng}$ (per replicate) of high-quality total RNA (RNA integrity number between 8 and 9.7) using the Illumina TruSeq Stranded mRNA LT sample preparation kit (Illumina, Hayward, CA, USA) according to the manufacturer's instructions. The cDNA libraries were then sequenced (101-bp paired-end read) on an Illumina HiSeq 2500 sequencer (Illumina, Hayward, CA, USA) according to the manufacturer's instructions. Low-quality reads $(<100$ base pairs) and adapter sequences in the libraries were then removed using Illumina build software (Illumina, Hayward, CA, USA). Overall, four transcriptome sequences were generated from our samples (two each for control or exposed larvae). We deposited the raw transcriptomes at the Sequence Read Archive (SRA) of the National Center for Biotechnology Information (NCBI), USA, under study accession number PRJNA560504.

\section{Identification and validation of responsive transcripts in An. gambiae s.s RNA to M. koenigii leaf extract}

We separately assessed the quality of each library using FastQC software [27] and used the results to filter and trim out low-quality sections of the reads using CLC Genomic Workbench version 9.0 software (CLC Bio, Aarhus, Denmark). We then obtained the protein-coding gene set AgamP4.4 of An. gambiae s.s from VectorBase [28] and mapped the filtered and trimmed reads to the gene set (AgamP4.4) using RNA-Seq analysis procedures in CLC Genomic Workbench software version 9.0 (CLC Bio, Aarhus, Denmark) as described previously [29]. Briefly, we mapped the reads through settings that allowed two mismatches per read (with a maximum of 10 hits per read), with at least $80 \%$ of each read matching the gene at $95 \%$ identity. We then used reads per kilobase per million (RPKM) mapped reads as a proxy for quantity (abundance) of transcripts [30] for (1) assessment of baseline transcriptional processes that underpin the larval developmental stage in the mosquito (in the absence of xenobiotics) and (2) comparison of relative expression of the genes between libraries from control and exposed larvae. We established the relative number of reads for each transcript in relation to the total read counts for each RNA-seq library to calculate the $p$-value based on Baggerly's test method following Bonferroni analysis [31]. We then determined the relative fold change (FC) of transcripts between the control and exposed mosquito larvae as a ratio of the RPKM values and normalized based on the number of reads obtained from each library using an inbuilt algorithm in CLC Genomic Workbench. The normalized values were used in this study. We considered transcripts differentially expressed (DE) between the libraries if they had a normalized value of at least (i) 1.5-fold change, (ii) corrected $p<0.05$ false discovery rate (FDR), (iii) ten RPKM and (iv) a support of ten unique read mappings. We defined fold change as a ratio of RPKM values between those from exposed and control larvae libraries. We thus considered and categorized these transcripts as specific to control or exposed larval libraries.

We also conducted gene ontology (GO) enrichment analyses of differentially expressed transcripts in exposed 
relative to control larvae libraries using gProfiler [32] to establish pathways, networks and interactions associated with transcripts induced or suppressed by the exposure of larvae to the extract. For these analyses, we set our thresholds to a significance of $p=0.05$ (to retrieve all GO terms under the biological process, molecular function and cellular component) and ordered query to identify specific functional terms associated with the most significant changes for our query [33]. Since the extract predominantly induced morphogenetic abnormalities in the larvae [11] that we putatively associate a priori with cuticular metabolism [34,35], which changes with developmental stages in insects [36], we further focused our analyses on cuticular proteins (CPs). We consequently detected and classified putative structural CPs among the DE transcripts through blastp [37] searches against the AgamP4.4 gene set of An. gambiae s.s from VectorBase [28] and CutProtFam-Pred CPs family prediction tool $[38,39]$. The tool classified the CPs into protein families that (i) exhibited Rebers and Riddiford (R\&R) Consensus sequences (CPR) [38, 40], (ii) were based on a conserved region with a 44 amino acid motif (CPF) and (iii) were analogous to peritrophins with chitin-binding domains (CPAP). The tool further classified the CPR into RR-1, RR-2 and RR-3 subfamilies based on variations in their consensus amino acid sequences in the $R \& R$ domain [38] and identified cuticular proteins of low complexity (CPLC), which encompass CPLCA, CPLCP and CPLCX among our differentially expressed transcripts.

\section{Validation of transcriptome expression profiles using RT-qPCR}

\section{Reverse transcriptions of larval RNA transcripts}

We further evaluated whether our RNA-Seq analysis results could be independently replicated using the quantitative reverse transcription polymerase chain reaction (RT-qPCR) technique as an independent tool. We randomly selected DE larval transcripts in our RNAseq library and compared their relative fold changes to those we obtained for the same transcripts through RTqPCR. Briefly, we generated five independent biological replicates (exposed and control) of the larvae, extracted and cleaned the respective total RNA libraries from our control and exposed larvae ab initio. We used the same methods and procedures we used to prepare the biological samples for the RNA-seq component of our study for sample preparations and total RNA extraction. We then reverse transcribed $1 \mu \mathrm{g}$ of the total RNA using the iScript $^{\mathrm{TM}}{ }^{\mathrm{c}}$ DNA synthesis kit (BIO-RAD, Hercules, USA) on the Arktik thermal cycler (Thermo Scientific, USA), according to the manufacturer's protocol.

\section{Selection of candidate transcripts for RT-qPCR}

We randomly selected eight $\mathrm{DE}$ transcripts for validation of differential expression. These transcripts were significantly induced or suppressed in the exposed larvae library relative to the control library to encompass and validate differential expression in both directions (up- and downregulated genes) of the libraries. We also selected four transcripts that were neutral (neither induced nor suppressed in the exposed library relative to the control library) as potential internal reference neutral/loading controls [41]. These reference transcripts consisted of CLIP-domain serine protease, glyceraldehyde 3-phosphate dehydrogenase (gapdh) and two uncharacterized genes (Additional file 1: Table S1) from VectorBase [28]. We ensured that all these transcripts were abundantly expressed in the RNA-seq libraries (based on their RPKM values) to ensure that their expression levels would be within the sensitivity of our Stratagene MX3005P RTqPCR machine (Agilent Technologies, CA, USA). We obtained DNA sequences of respective genes from VectorBase [28] using the respective gene IDs (Additional file 1: Table S1) and designed primers (Additional file 1: Table S1) from these sequences in silico using primer3 software [42]. In all cases, we ensured that the melting $\left(T_{\mathrm{m}}\right)$ and annealing temperatures of the respective forward and reverse primers generated were similar, as determined by pDRAW32 version 1.1.142 software (http://www.acaclone.com) (Additional file 1: Table S1).

\section{Real-time qRT-PCR of genes for DE transcripts}

We first interrogated reference transcripts for their stable expression by performing RT-qPCR in three technical replicates for each of the five biological replicates on our Strategene MX3005P RT-qPCR machine (Agilent Technologies, CA, USA) using Fast SYBR Green I Master Mix (Applied Biosystems, Carlsbad, CA) according to the manufacturer's instructions. We performed the PCR in reaction volumes of $10 \mu \mathrm{l}$ for each replicate consisting of $1 \mu \mathrm{g}$ cDNA template in three independent replicates with $5 \mu \mathrm{l}$ of Fast SYBR Green Master Mix (Applied Biosystems, Carlsbad, CA, USA) in the presence of 0.4 picomoles of specific primers for the respective candidate reference transcripts. We carried out the reactions in a RT-qPCR thermal cycler (Stratagene MX3005P, Agilent Technologies, CA, USA) according to the manufacturer's instructions. We involved thermo-cycling conditions that included an initial step of $95{ }^{\circ} \mathrm{C}$ for $10 \mathrm{~min}, 40$ cycles of $95{ }^{\circ} \mathrm{C}$ for $30 \mathrm{~s}, 55.0-63.2{ }^{\circ} \mathrm{C}$ (Additional file 1: Table S1) for $45 \mathrm{~s}$ and $72{ }^{\circ} \mathrm{C}$ for $1 \mathrm{~min}$, followed by one cycle of $95{ }^{\circ} \mathrm{C}$ for $1 \mathrm{~min}, 55^{\circ} \mathrm{C}$ for $30 \mathrm{~s}$ and $95{ }^{\circ} \mathrm{C}$ for $30 \mathrm{~s}$ for all the genes. We then assessed stability (non-differential 
expression) of these reference transcripts using BestKeeper software [43]. From this assessment, we identified gapdh and CLIP-domain serine protease transcripts as less variable [with a standard deviation of crossing point (CP) of 0.56 and 0.65 , respectively] among the reference transcript candidates. We thus adopted these two genes as our internal housekeeping transcripts for assessment of expression of the eight randomly selected transcripts. We then separately performed the RT-qPCR for each of these transcripts under similar reaction and thermocycling conditions as had been previously employed in the assessment for stable expression of the reference transcripts above, but with gapdh and CLIP-domain serine protease as internal reference/loading controls.

\section{Data analysis}

We computed and compared relative expression (means, fold changes and $p$-value) of the eight transcripts using Relative Expression Software Tool (REST)-384 version 2 software [44]. We then used these data to evaluate validity of the transcriptomes by comparing the fold changes obtained here (RT-qPCR) to those obtained earlier (RNA-Seq) for the eight genes through Pearson correlation analysis.

\section{Results}

Survivorship of An. gambiae mosquito larvae exposed to the extract and non-exposed control

We have summarized and presented data on the survivorship of An. gambiae mosquito larvae exposed to the extract and non-exposed control in Fig. 1a, b. We observed initial pupation at 4 and 11 dpe for control and exposed larvae, respectively. Most pupae (96\%) from the extract-exposed larvae populations did not eclose. At the point of sample collection, 53 and $81 \%$ of the larvae had pupated or eclosed for the extract-exposed and control populations respectively. Therefore, at peak pupation for the exposed population (18 dpe) the larvae were potentially abnormal. Thus, the subsequent RNA-Seq libraries consisted of the normal control and the abnormal exposed larvae populations.

\section{Mapping statistics of larval RNA-seq reads on the $A n$. gambiae s.s gene set}

We achieved a Pearson correlation coefficient of 0.978 (Additional file 3: Text S1), indicating a 97.8\% correlation in expression between RNA-seq and qRT-PCR results and effectively validating the transcriptomes. We obtained $\approx 80$ to 191 million reads from sequencing the An. gambiae s.s larval libraries (Fig. 2a). The variation in the number of reads obtained is due to the different depths we achieved in the sequencing of each library. We successfully mapped $65-70 \%$ of these reads onto the protein-coding gene set AgamP4.4 of An. gambiae s.s from VectorBase [28], among which 58.1-62.3 \% mapped uniquely to specific transcripts. Most of the transcripts had between 101 and 10,000 uniquely mapped reads (Fig. 2a).

Our assessment of baseline transcriptional processes that underpin the larval developmental stage in the mosquito (in the absence of xenobiotics) identified ribosomal, cuticular, hexamerins, cytochrome, elongation factor and muscle-related proteins as abundantly expressed transcripts (Fig. 2b; Additional file 2: Table S2). About $23.5 \%$ (47) of the 200 top-most abundantly expressed transcripts were differentially expressed between the libraries, among which expression of most (42) of the transcripts were suppressed in the exposed larvae libraries relative to those of control larvae (Fig. 3a).

\section{Differentially expressed and enriched pathways between control and exposed An. gambiae larvae libraries}

About $4.66 \%$ (730) of the transcripts were differentially expressed between the control and exposed libraries, most of which $(65.75 \%)$ were induced by the extract in the exposed libraries (Fig. 3b). The differentially expressed transcripts were predominantly associated with CPs $(5.75 \%)$, cholesterol homeostasis (0.55\%), osiris $(0.82 \%)$, juvenile hormone metabolism $(1.10 \%)$, transporters $(0.82 \%)$, immunity $(2.20 \%)$, redox balance and detoxification $(2.88 \%)$ associated gene families among others (1.10\%) (Fig. 4). Most (52.4\%) of the CPs belonged to the CPR family, within which expression of the RR-2 subfamily was suppressed by the exposure to the extract (Fig. 4a). Expressions of CPLC and CPF families were similarly suppressed and those of CPAP1 induced by the exposure to the extract (Fig. 4a). The exposure also suppressed expression of four NiemannPick type C-2 transcripts involved in cholesterol homeostasis (Fig. 4b) while inducing expression of 6 osiris (Fig. 4c), 7 carboxylesterase juvenile hormone esterase (COEJHE) (Fig. 4d), ATP-binding cassette (ABC) transporters (Fig. 4e), 10 immune-related (Fig. 4f) and 11 detoxification associated transcripts (Fig. 4g). The extract exposure suppressed expression of eight C-type lysozymes (Fig. 4f) and four glutathione $\mathrm{S}$ transferases (Fig. 4g). Fatty acid elongation and chitin-binding networks were induced while putrescine and ornithine metabolism, ornithine decarboxylase activity, cell wall remodeling, cuticular structural constituents and hydrolytic activities were suppressed by the exposure as revealed by GO analyses (Table 1). 


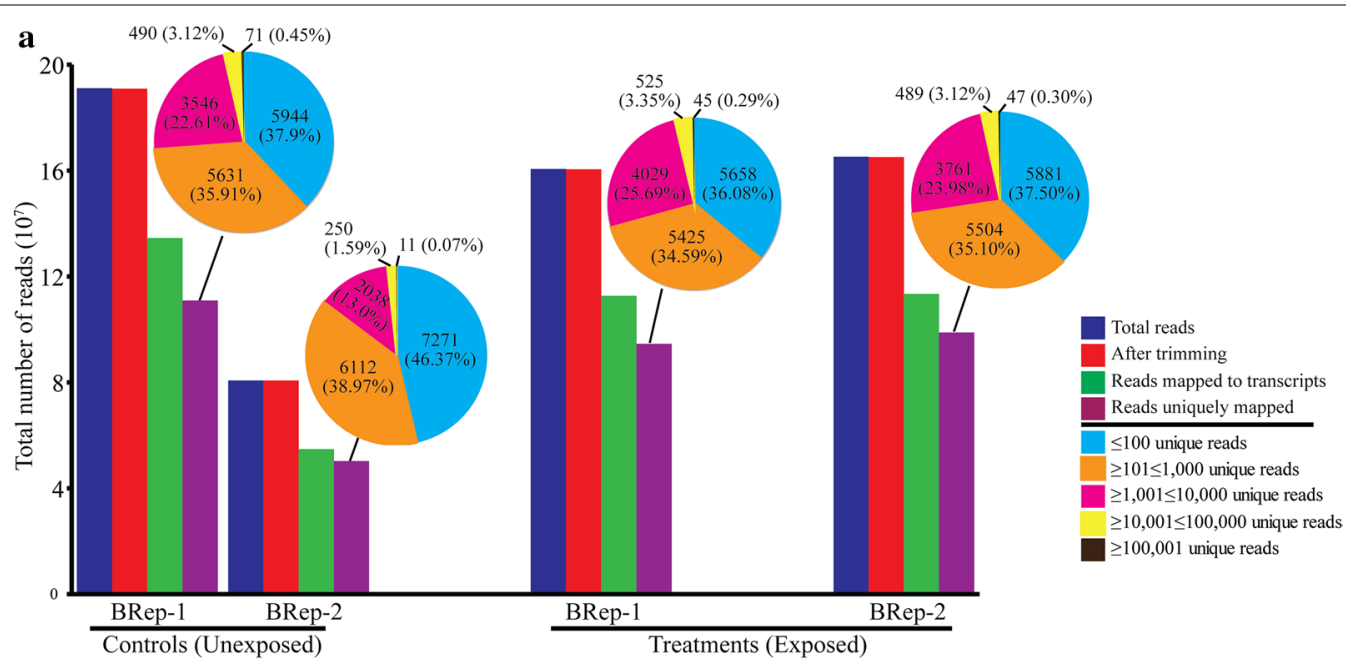

b

\begin{tabular}{|c|c|c|c|}
\hline VectorBase Description & $N(\%)$ & Reads Range & RPKM Range \\
\hline 18S rRNA: 18S ribosomal RNA & $1(0.5)$ & 99918 & 63971.23 \\
\hline ADP, ATP carrier protein 1 & $1(0.5)$ & 198005 & 126390.20 \\
\hline Alpha amylase: amylase & $1(0.5)$ & 87230 & 59477.93 \\
\hline ATP-dependent RNA helicase DBP2 & $1(0.5)$ & 67637 & 41436.43 \\
\hline ATP6: adenosine triphosphatase subunit 6 & $1(0.5)$ & 98490 & 164088.01 \\
\hline Ca-P60A: calcium-transporting ATPase sarcoplasmic/endoplasmic reticulum type & $1(0.5)$ & 292463 & 188828.17 \\
\hline Chondroitin proteoglycan- 2 & $1(0.5)$ & 25034 & 29812.60 \\
\hline Chymotrypsin-like protease & $1(0.5)$ & 48782 & 33851.84 \\
\hline citrate synthase & $1(0.5)$ & 31373 & 32064.78 \\
\hline Cofilin & $1(0.5)$ & 29308 & 30429.73 \\
\hline Cre: calreticulin & $1(0.5)$ & 49884 & 35071.56 \\
\hline Creatine kinase & $1(0.5)$ & 484371 & 364891.84 \\
\hline Cysteine-rich venom protein & $1(0.5)$ & 33380 & 45385.09 \\
\hline Enolase & $1(0.5)$ & 61602 & 47881.63 \\
\hline Eukaryotic translation initiation factor $4 \mathrm{~A}$, isoform 2 & $1(0.5)$ & 68654 & 54331.26 \\
\hline Fatty acyl-CoA reductase & $1(0.5)$ & 37093 & 31569.42 \\
\hline GAPDH: glyceraldehyde 3-phosphate dehydrogenase & $1(0.5)$ & 65117 & 56908.67 \\
\hline GPROP6: long wavelength sensitive opsin 6 & $1(0.5)$ & 54414 & 46932.02 \\
\hline Heat shock $70 \mathrm{kDa}$ protein $1 / 8$ & $1(0.5)$ & 226711 & 133990.43 \\
\hline Lp: lipophorin & $1(0.5)$ & 219431 & 121647.77 \\
\hline Isu rRNA: & $1(0.5)$ & 3622409 & 1555660.76 \\
\hline LYSC3: C-Type Lysozyme. & $1(0.5)$ & 43262 & 46426.62 \\
\hline Metalloendopeptidase & $1(0.5)$ & 91643 & 75559.49 \\
\hline Methylmalonate-semialdehyde dehydrogenase (acylating), mitochondrial & $1(0.5)$ & 39391 & 27966.02 \\
\hline ND4: NADH dehydrogenase subunit 4 & $1(0.5)$ & 29180 & 27961.22 \\
\hline Niemann-Pick Type C-2 & $1(0.5)$ & 47386 & 38223.33 \\
\hline Nucleoside-diphosphate kinase & $1(0.5)$ & 38817 & 42095.97 \\
\hline OBP9: odorant binding protein 9 & $1(0.5)$ & 60601 & 60021.76 \\
\hline Paramyosin & $1(0.5)$ & 74960 & 44719.26 \\
\hline polyubiquitin & $1(0.5)$ & 42761 & 40618.00 \\
\hline Rack1: guanine nucleotide-binding protein subunit beta-like protein & $1(0.5)$ & 88765 & 72719.91 \\
\hline SAP3: sensory appendage protein 3 & $1(0.5)$ & 125887 & 92834.29 \\
\hline Sarcoplasmic calcium-binding protein & $1(0.5)$ & 225682 & 147398.66 \\
\hline Sterol carrier protein 2 variant 2 & $1(0.5)$ & 61154 & 51193.50 \\
\hline SUI1: protein translation factor SUI1 & $1(0.5)$ & 39199 & 30985.34 \\
\hline Tctp: translationally-controlled tumor protein homolog & $1(0.5)$ & 198883 & 171138.33 \\
\hline Voltage-dependent anion-selective channel protein 2 & $1(0.5)$ & 40442 & 37535.23 \\
\hline 28S rRNA: $28 \mathrm{~S}$ ribosomal RNA & $2(1)$ & $60464-89224$ & $38285.66-56301.23$ \\
\hline Aldo: fructose biphosphate aldolase & 2(1) & $52332-55332$ & $34836.30-35816.33$ \\
\hline Tubulin & 2(1) & $42260-49138$ & $30758.81-40832.85$ \\
\hline Eupolytin & $3(1.5)$ & $41458-89676$ & $33049.34-72869.08$ \\
\hline F-type $\mathrm{H}+$-transporting ATPase subunit alpha & $3(1.5)$ & $23109-90309$ & $30009.90-60113.50$ \\
\hline Tropomyosin & $3(1.5)$ & $52778-138386$ & $42342.49-88422.05$ \\
\hline Troponin protein & $3(1.5)$ & $36721-155381$ & $36212.72-105250.18$ \\
\hline Cytochrome protein & $4(2)$ & $115029-541120$ & $233826.20-506246.73$ \\
\hline Elongation factor & 4(2) & $31457-463346$ & $33721.33-331844.62$ \\
\hline Hexamerin & $4(2)$ & $118304-318480$ & $77148.51-223497.57$ \\
\hline Myofilin & $4(2)$ & $45532-291052$ & $28668.31-310103.48$ \\
\hline Actin & $5(2.5)$ & $49804-164018$ & $30295.72-116855.82$ \\
\hline Cuticular protein & $9(4.5)$ & $12771-79072$ & $29609.24-217254.75$ \\
\hline 40 S ribosomal protein & $33(16.5)$ & $21301-129865$ & $27984.80-197468.90$ \\
\hline Unknown protein & $36(18)$ & $16101-410493$ & $28107.72-363059.30$ \\
\hline $60 \mathrm{~S}$ ribosomal protein & $46(23)$ & $29759-151443$ & $32785.75-243071.45$ \\
\hline
\end{tabular}

Fig 2 Overview of RNA-seq analysis of Anopheles gambiae larvae exposed to the Murraya koenigii bioactive fraction. a Processing of RNA-seg reads from Anopheles gambiae larvae and mapping statistics of the reads. b Summary of the top 200 most abundantly expressed (RPKM) genes in the control larvae 


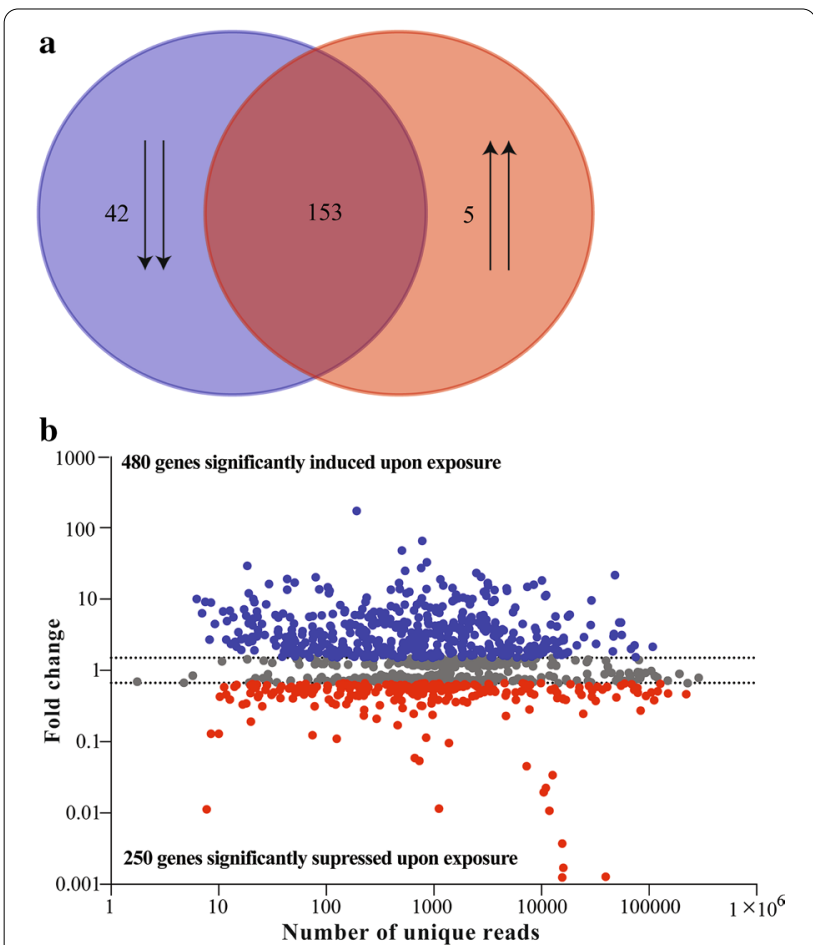

Fig 3 Differential expression of transcripts exhibiting significant expression in exposed larvae. a Spatial distribution of differential expression in the top 200 most abundant (RPKM) genes of the transcriptome. $\mathbf{b}$ The MA plot showing differentially expressed genes between control and exposed An. gambiae larvae

\section{Discussion}

In this study, we used high-throughput RNA-seq expression analysis to determine transcriptional responses in third-fourth instar normal control and abnormal exposed larvae population exposed to sub-lethal concentrations of curry tree $(M$. koenigii) leaf extracts. The extract previously induced morphogenetic abnormalities, reduced locomotion and delayed pupation in the larvae and was predominantly composed of alkaloid phytochemicals (neplanocin A, 3-(1-naphthyl)-L-alanine, lumiflavine, terezine $C$, agelaspongin and murrayazolinol compounds) [11]. We did not age-match control and exposed populations because of the extract-induced delay in pupation of the exposed relative to control larvae coupled to our need to compare $\mathrm{L}_{3} / \mathrm{L}_{4}$ populations between the treatments (exposed $v s$ control). Thus, our molecular results would reflect responses to the inevitable combination of age differences between the larvae populations and the xenobiotic (extract) challenge. We hereinafter refer to this combination as 'exposed' and the unexposed normal control as 'control' treatments.

We initiated our study by establishing baseline transcriptional processes (molecular investments) that underpin the larval developmental stage in the mosquito control (in the absence of xenobiotics). Our evidence suggests a significant investment in the development and reorganization of musculature in the larvae as evidenced by preferential expression of muscle and cytoskeleton related transcripts [45] in our study. We observed potentially enhanced investment in larval molting and pupation as shown by predominant expression of hexamerins in the larvae. The hexamerins are conserved hemolymph proteins secreted by larval fat body [46] and facilitate larvae-pupae transition [47]. Hexamerins facilitate these processes through regulation of protein reserves (for amino acids and energy) [48], transport of ecdysteroids [49] and juvenile hormone ( $\mathrm{JH})$ [50]. We were thus interested in understanding how these and related processes were affected by the extract exposure treatment we have described above in relation to the associated phenotypes we observed in the larvae [11].

Our analysis of processes affected by exposure to the extract revealed the impairment of exoskeleton development, immunity, detoxification processes and transport system by the exposure. Most affected processes were associated with the cuticle that typically protects insects against adverse environmental conditions and pathogens [36]. In that respect, the extract appeared to soften the cuticle through reduced transcription of the RR-2 subfamily of the CPR cuticle family $[40,51]$ that encodes hard cuticle proteins of the insect exoskeleton [52] and CPLC genes implicated in increasing the thickness of the cuticle through forming rigid matrices [53]. The reduction in hard cuticle synthesis could in turn enhance susceptibility of the larvae to insecticides [54], including pyrethroids [55]. The reduced synthesis is also a possible precursor to the post-ecdysial molting deformities [56] we previously observed in this mosquito [11]. The suppression of the RR-1 subfamily, CPLCPs, CPFs and Niemann-Pick Type C-2 transcripts, and putrescine, ornithine and ornithine decarboxylase pathways could cause enhancement of the deformities due to the exposure. Suppression of the RR-1 subfamily, CPLCPs and CPFs has been shown to potentially interrupt endocuticle development and impede ecdysis, consequently enhancing molting deformities in the mosquito [56, 57]. Niemann-Pick type C-2 controls sterol homeostasis and steroid biosynthesis precursors for ecdysteroids [58]. The ecdysteroids in turn induce larval molting and metamorphosis [59] and promote pupal commitment at $\mathrm{L}_{4}$ [60]. The putrescine, ornithine and ornithine decarboxylase pathways are critical for optimal tissue growth and development [61]. Suppression of their expression in our study potentially perturbs cellular processes essential for cytoskeletal structure in the larvae [62]. The interruption of endocuticle development and ecdysis was putatively 


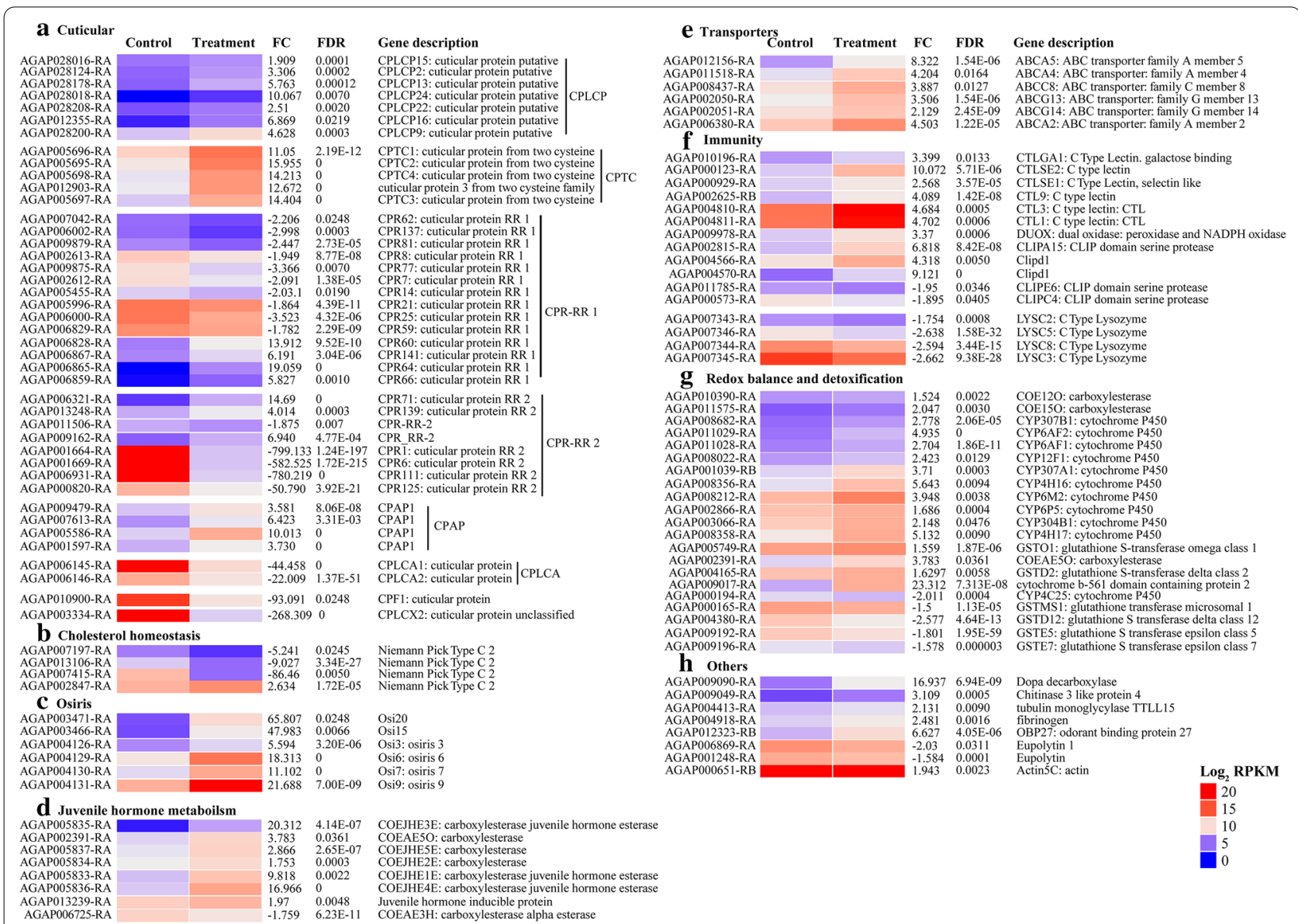

Fig. 4 Heat maps representing differentially expressed genes in respective functional categories $(\mathbf{a}-\mathbf{h})$. Heat maps were obtained by plotting the normalized expression profiles (RPKM, $\log _{2}$ transformed) of individual genes in control and exposed An. gambiae larvae in the R-package software. The heat maps were clustered using Euclidean distance calculation and D. Ward clustering methods. The clusters were then manually separated to various functional categories

enhanced by potentially untimely (18 dpe) induction of carboxylesterases juvenile hormone esterase (COEJHE) expression, which could adversely affect pupation [63]. The induction of COEJHE potentially decreased JH hormone titers [64] and initiated a premature pupation process by changing tissue commitment from larval tissue synthesis to production of pupal tissues [65]. This potentially induced the larvae-pupae-transition arrest in our previous observation [11]. The extract appears to target cuticle metabolism in regulating the growth of the larvae.

The larvae putatively counteracted the exposure treatment through induction of osiris, ATP-binding cassette (ABC) transporters, cytochrome P450s (CYPs) and carboxylesterases transcripts and pathways associated with fatty acid (FA) elongation and chitin binding. These transcripts and pathways potentially facilitated interim survival of the larvae in the xenobiotic (extract) permeated aquatic environment. Osiris facilitates the phenotypic plasticity and toxicity responses essential in development, toxicology defenses and digestion in insects [66]. The ATP-binding cassette (ABC) transporters and CYPs facilitate transformation and elimination of endogenous and exogenous compounds including insecticides [67] and phytochemicals [68] by insects. The fatty acid (FA) elongation and chitin-binding pathways trigger intrinsic adaptation mechanisms in insects $[55,69]$. However, the detoxification process appeared to be potentially counteracted by suppression of glutathione $\mathrm{S}$ transferase (GST) expression by the extract. This group of supressed GSTs is associated with the reduction of oxidative stress in mosquitoes since not all GSTs are involved in reducing oxidative stress [70]. The reduction in GSTs could have also exposed the larvae to oxidative stress [70], suppressed their immunity to bacterial infection [71] and hence enhanced their susceptibility to exogenous phytochemicals [72]. The immunity appears to have been further depressed by suppressed expression of C-type lysozyme in the larvae by the exposure. Lysozymes 
Table 1 Gene ontology enrichment analysis of differentially expressed transcripts in exposed relative to control larvae libraries

\begin{tabular}{|c|c|c|c|c|c|}
\hline & GO category & Gene ontology ID & Description of pathway & Test (Ref) & $p$-value \\
\hline \multirow[t]{32}{*}{ Induced } & \multirow[t]{12}{*}{ Biological processes } & GO:0006508 & Proteolysis & $58(459)$ & 0.0003 \\
\hline & & GO:0006030 & Chitin metabolic process & $11(210)$ & 0.0025 \\
\hline & & GO:1901071 & Glucosamine-containing compound metabolic process & $11(210)$ & 0.0034 \\
\hline & & GO:0006040 & Amino sugar metabolic process & $11(210)$ & 0.0040 \\
\hline & & GO:0019367 & Fatty acid elongation, saturated fatty acid & $2(4)$ & 0.0074 \\
\hline & & GO:0019368 & Fatty acid elongation, unsaturated fatty acid & $2(4)$ & 0.0074 \\
\hline & & GO:0034625 & Fatty acid elongation, monounsaturated fatty acid & $2(4)$ & 0.0074 \\
\hline & & GO:0034626 & Fatty acid elongation, polyunsaturated fatty acid & $2(4)$ & 0.0074 \\
\hline & & GO:0006022 & Aminoglycan metabolic process & $11(210)$ & 0.0090 \\
\hline & & GO:0030497 & Fatty acid elongation & $2(4)$ & 0.0090 \\
\hline & & GO:0000038 & Very long-chain fatty acid metabolic process & $2(4)$ & 0.0099 \\
\hline & & GO:0042761 & Very long-chain fatty acid biosynthetic process & $2(4)$ & 0.0099 \\
\hline & \multirow[t]{3}{*}{ Cellular component } & GO:0005576 & Extracellular region & $41(210)$ & 0.0000 \\
\hline & & GO:0044421 & Extracellular region part & $23(185)$ & 0.0000 \\
\hline & & GO:0005615 & Extracellular space & $28(363)$ & 0.0000 \\
\hline & \multirow[t]{16}{*}{ Molecular function } & GO:0016787 & Hydrolase activity & $96(457)$ & 0.0000 \\
\hline & & GO:0004175 & Endopeptidase activity & $36(404)$ & 0.0000 \\
\hline & & GO:0070011 & Peptidase activity, acting on I-amino acid peptides & $42(404)$ & 0.0001 \\
\hline & & GO:0008233 & Peptidase activity & $42(404)$ & 0.0002 \\
\hline & & GO:0008061 & Chitin binding & $12(228)$ & 0.0006 \\
\hline & & GO:0003824 & Catalytic activity & $163(457)$ & 0.0017 \\
\hline & & GO:0008236 & Serine-type peptidase activity & $21(261)$ & 0.0025 \\
\hline & & GO:0017171 & Serine hydrolase activity & $21(261)$ & 0.0025 \\
\hline & & GO:0004252 & Serine-type endopeptidase activity & $20(261)$ & 0.0030 \\
\hline & & GO:0102338 & 3-oxo-lignoceronyl-coa synthase activity & $2(4)$ & 0.0036 \\
\hline & & GO:0102337 & 3-oxo-cerotoyl-coa synthase activity & $2(4)$ & 0.0036 \\
\hline & & GO:0102756 & Very-long-chain 3-ketoacyl-coa synthase activity & $2(4)$ & 0.0036 \\
\hline & & GO:0102336 & 3-oxo-arachidoyl-coa synthase activity & $2(4)$ & 0.0036 \\
\hline & & GO:0009922 & Fatty acid elongase activity & $2(4)$ & 0.0036 \\
\hline & & GO:0052689 & Carboxylic ester hydrolase activity & $10(257)$ & 0.0046 \\
\hline & & GO:0004312 & Fatty acid synthase activity & $2(4)$ & 0.0056 \\
\hline & KEGGc & KEGG:04142 & Lysosome & $10(435)$ & 0.0027 \\
\hline \multirow[t]{16}{*}{ Suppressed } & \multirow[t]{8}{*}{ Biological Processes } & GO:0016998 & Cell wall macromolecule catabolic process & $4(132)$ & 0.0005 \\
\hline & & GO:0044036 & Cell wall macromolecule metabolic process & $4(132)$ & 0.0008 \\
\hline & & GO:0071554 & Cell wall organization or biogenesis & $4(132)$ & 0.0019 \\
\hline & & GO:0009445 & Putrescine metabolic process & $2(13)$ & 0.0041 \\
\hline & & GO:0009446 & Putrescine biosynthetic process & $2(13)$ & 0.0041 \\
\hline & & GO:0033387 & Putrescine biosynthetic process from ornithine & $2(13)$ & 0.0041 \\
\hline & & GO:0006591 & Ornithine metabolic process & $2(13)$ & 0.0061 \\
\hline & & GO:0050830 & Defense response to gram-positive bacterium & $3(38)$ & 0.0090 \\
\hline & \multirow[t]{8}{*}{ Molecular function } & GO:0042302 & Structural constituent of cuticle & $11(124)$ & 0.0001 \\
\hline & & GO:0003796 & Lysozyme activity & $4(132)$ & 0.0003 \\
\hline & & GO:0004586 & Ornithine decarboxylase activity & $2(13)$ & 0.0018 \\
\hline & & GO:0004553 & Hydrolase activity, hydrolyzing o-glycosyl compounds & $6(80)$ & 0.0031 \\
\hline & & GO:0008236 & Serine-type peptidase activity & $13(116)$ & 0.0032 \\
\hline & & GO:0017171 & Serine hydrolase activity & $13(116)$ & 0.0032 \\
\hline & & GO:0070011 & Peptidase activity, acting on I-amino acid peptides & $16(103)$ & 0.0032 \\
\hline & & GO:0061783 & Peptidoglycan muralytic activity & $3(38)$ & 0.0033 \\
\hline
\end{tabular}


Table 1 (continued)

\begin{tabular}{|c|c|c|c|c|}
\hline GO category & Gene ontology ID & Description of pathway & Test (Ref) & $p$-value \\
\hline & GO:0008233 & Peptidase activity & $16(103)$ & 0.0039 \\
\hline & GO:0016798 & Hydrolase activity, acting on glycosyl bonds & $6(80)$ & 0.0074 \\
\hline & GO:0004252 & Serine-type endopeptidase activity & $12(116)$ & 0.0075 \\
\hline & GO:0003824 & Catalytic activity & $82(210)$ & 0.0082 \\
\hline & GO:0016787 & Hydrolase activity & $24(84)$ & 0.0090 \\
\hline
\end{tabular}

Significantly enriched pathways determined through gProfiler [32]

Test: genes in the differentially expressed dataset; Ref:Entire Anopheles genes in gProfiler database; ${ }^{C}$ : Kyoto Encyclopedia of Genes and Genomes (KEGG)

degrade macromolecules including toxic phytochemicals and have a potential role in innate immunity [73]. The exposure induced the C-type lectin (CTL) immune transcripts [74] in the larvae. The underlying physiological processes underpinning this (CTL) immune response remain to be determined. We similarly observed induction of CPAP, whose role has not been elucidated in $A n$. gambiae [75]. Survival in the larvae in the presence of the extract seems to be dependent on opposing forces between those counteracting and those facilitating susceptibility of the larvae to xenobiotics, which include our extract phytochemicals. Overall, our studies reveal significant modulation of several transcripts, some of which may not be directly related to our treatments, but are inherently perturbed, irrespective of external stimuli in the mosquito. These transcripts can potentially be identified from the rest of the differentially expressed transcripts through carefully planned and executed functional genomics studies.

These results have potential implications for integrated vector management (IVM) of An. gambiae s.s mosquitoes. First, the exposure treatment appears to impair the cuticular integrity in the larvae, which enhances susceptibility of the larvae to insecticides. This suggests that the exposure treatment can augment the efficacy of insecticide formulations to surmount resistance to insecticides in the mosquito. The current studies were limited to the $\mathrm{L}_{3} / \mathrm{L}_{4}$ instar larval stages of the mosquito, necessitating further studies to establish the efficacy of the extract against younger larvae (below $\mathrm{L}_{3}$ instar) and pupae but comparing their underlying molecular processes. Second, the larvae appear to counteract the effect of exposure by instigating adaptive mechanisms, which can be further investigated through generational laboratory or natural chronic exposure experiments and assessment of the resultant biological cost of the adaptation to fitness in the mosquito. The findings will provide additional insight into the impact of such adaptation on the vectorial capacity of the mosquito following temporal exposures of the larvae. The exposure appears to perturb $\mathrm{JH}$ metabolism probably because of the Neplanocin A constituent of the extract [11]. Neplanocin A has a similar inhibition effect on $\mathrm{JH}$ action as 3-deazaneplanocin A in mosquitoes [11,
76], suggesting potential application of Neplanocin $\mathrm{A}$ as a potent $\mathrm{JH}$ antagonists. However, these putative responses present challenges and are confounded by age (exposed larvae were older) and physiological compromise (abnormal) in the larvae.

\section{Conclusions}

Anopheles gambiae s.s larvae heavily invest in cuticular development, which was disrupted by the exposure treatment. This disruption (exposure) potentially induced the gross morphogenic abnormalities that we previously observed in the larvae exposed to the extract [11]. The cuticle genes can potentially be targeted in the development of more efficacious curry tree phytochemical-based IGRs against An. gambiae s.s mosquito larvae. Survival of the larvae in the presence of the extract appears to be dependent on their ability to withstand oxidative stress associated processes induced by the extract. Further studies may adapt these findings for IVM against $A n$. gambiae s.s. However, such studies should be preceded by validation evaluations that will effectively break down the individual effects of the extract exposure from the confounding factors of age and larvae abnormality we have alluded to above in our results.

\section{Supplementary Information}

The online version contains supplementary material available at https://doi. org/10.1186/s13071-020-04505-4.

Additional file 1: Table S1. Primers utilized for An. gambiae larvae RNAtranscriptome validation.

Additional file 2: Table S2. Analysis of An. gambiae larvae RNA-seq libraries. Sheet 1. RNAseq dataset output of An. gambiae larvae transcripts. Sheet 2. Differentially Expressed genes (FC $\geq 1.5$ ) Sheet 3. The top 200 most abundant transcripts (RPKM) in the control An. gambiae larvae differentially expressed library.

Additional file 3: Text S1. Validation of An. gambiae RNA-seq results with qPCR.

\section{Acknowledgements}

We thank Mr. John Bwire (ICIPE) for the technical and operational support during the project lifespan and Mr. Richard Otieno (ICIPE) for assisting in maintenance of the mosquito colony. We also gratefully acknowledge logistical support for this research from Kenyatta University and ICIPE. 


\section{Authors' contributions}

CMM, AH, and POM conceived and designed experiments, FMK, EOA and POM contributed experiment reagents, materials and analysis tools, CMM and FLOO performed the experiments, CMM, EOA and POM analyzed the data, CMM and EOA developed the manuscript, CMM, FMK, AH, FLOO, EOA and POM reviewed the manuscript. All authors read and approved the final manuscript.

\section{Funding}

The work was supported by Grand Challenges Canada www.grandchallenges. ca/ (Grant number: 02691). The views expressed herein do not necessarily reflect the official opinion of the donors.

\section{Availability of data and materials}

The raw transcriptomes datasets generated and/or analyzed during the current study are available in the Sequence Read Archive (SRA) of the National Center for Biotechnology Information (NCBI), USA, under the study Accession number PRJNA560504

\section{Ethics approval and consent to participate}

Not applicable.

\section{Consent for publication}

Not applicable.

\section{Competing interests}

The authors declare that they have no competing interests.

\section{Author details}

${ }^{1}$ Department of Biochemistry and Molecular Biology, Egerton University, Njoro Campus, PO Box 536-20115, Egerton, Kenya. ${ }^{2}$ Department of Biochemistry, Microbiology and Biotechnology, School of Pure and Applied Sciences, Kenyatta University, Ruiru Campus, PO Box 43844-00100, Nairobi, Kenya. ${ }^{3}$ International Centre of Insect Physiology and Ecology (ICIPE), Duduville Campus, Kasarani, PO Box 30772-00100, Nairobi, Kenya. ${ }^{4}$ Department of Biological Sciences, Meru University of Science and Technology, PO Box 972-60200, Meru, Kenya. ${ }^{5}$ Department of Chemistry, School of Pure and Applied Sciences, Kenyatta University, Ruiru Campus, PO Box 43844-00100, Nairobi, Kenya. ${ }^{6}$ Biotechnology Research Institute-Kenya Agricultural and Livestock Research Organization, PO Box 362-00902, Kikuyu, Kenya.

\section{Received: 4 June 2020 Accepted: 30 November 2020}

Published online: 02 January 2021

\section{References}

1. World Health Organization. World malaria report 2018. 4th ed. Geneva: World Health Organization; 2018.

2. Killeen GF, Marshall JM, Kiware SS, South AB, Tusting LS, Chaki PP, et al. Measuring, manipulating and exploiting behaviours of adult mosquitoes to optimise malaria vector control impact. BMJ Glob Health. 2017:2:e000212.

3. Ranson H, N'Guessan R, Lines J, Moiroux N, Nkuni Z, Corbel V. Pyrethroid resistance in African anopheline mosquitoes: what are the implications for malaria control? Trends Parasitol. 2011;27:91-8.

4. Ranson $\mathrm{H}$, Lissenden N. Insecticide resistance in African Anopheles mosquitoes: a worsening situation that needs urgent action to maintain malaria control. Trends Parasitol. 2016:32:187-96.

5. White MT, Griffin JT, Churcher TS, Ferguson NM, Basáñez MG, Ghani AC. Modelling the impact of vector control interventions on Anopheles gambiae population dynamics. Parasites Vectors. 2011;4:153.

6. Tusting LS, Thwing J, Sinclair D, Fillinger U, Gimnig J, Bonner KE, et al. Mosquito larval source management for controlling malaria. Cochrane Database Syst Rev. 2013;8:CD008923.

7. Worrall E, Fillinger U. Large-scale use of mosquito larval source management for malaria control in Africa: a cost analysis. Malar J. 2011;10:338.

8. Kweka EJ, Munga S, Himeidan Y, Githeko AK, Yan G. Assessment of mosquito larval productivity among different land use types for targeted malaria vector control in the western Kenya highlands. Parasites Vectors. 2015;8:356.

9. Jankowska M, Rogalska J, Wyszkowska J, Stankiewicz M. Molecular targets for components of essential oils in the insect nervous system-a review. Molecules. 2018;23:34
10. Salehzadeh A, Jabbar A, Jennens L, Ley SV, Annadurai RS, Adams R, et al. The effects of phytochemical pesticides on the growth of cultured invertebrate and vertebrate cells. Pest Manag Sci. 2002;58:268-76.

11. Mang'era CM, Hassanali A, Khamis FM, Rono MK, Lwande W, Mbogo C, et al. Growth-disrupting Murraya koenigii leaf extracts on Anopheles gambiae larvae and identification of associated candidate bioactive constituents. Acta Trop. 2019;190:304-11.

12. Innocent E, Gikonyo NK, Nkunya MH. Repellency property of long chain aliphatic methyl ketones against Anophelesgambiae s.s. Tanzan J Health Res. 2008;10:50-4.

13. Amer A, Mehlhorn H. Larvicidal effects of various essential oils against Aedes, Anopheles, and Culex larvae (Diptera, Culicidae). Parasitol Res. 2006;99:466-72.

14. Pineda-Cortel MRB, Cabantog RJR, Caasi PM, Ching CAD, Perez JBS, Godisan PGM, et al. Larvicidal and ovicidal activities of Artocarpus blancoi extracts against Aedes aegypti. Pharm Biol. 2019;57:120-4.

15. Ndungu M, Torto B, Knols BGJ, Hassanali A, et al. Laboratory evaluation of some eastern African Meliaceae as sources of larvicidal botanicals for Anopheles gambiae. Int J Trop Insect Sci. 2004;24:311-8.

16. Okumu FO, Knols BGJJ, Fillinger U. Larvicidal effects of a neem (Azadirachta indica) oil formulation on the malaria vector Anopheles gambiae. Malar J. 2007;6:63.

17. Mdoe FP, Cheng SS, Lyaruu L, Nkwengulila G, Chang S-T, Kweka EJ. Larvicidal efficacy of Cryptomeria japonica leaf essential oils against Anopheles gambiae. Parasites Vectors. 2014;7:426.

18. Samuel M, Oliver SV, Coetzee M, Brooke BD. The larvicidal effects of black pepper (Piper nigrum L.) and piperine against insecticide resistant and susceptible strains of Anopheles malaria vector mosquitoes. Parasites Vectors. 2016;9:238

19. Nyamoita MG, Ester I, Zakaria MH, Wilber L, Bwire OJ, Ahmed H. Comparison of the effects of extracts from three Vitex plant species on Anophelesgambiae s.s. (Diptera: Culicidae) larvae. Acta Trop. 2013;127:199-203.

20. Owino J, Hassanali A, Ndungu M. Bio-assay guided fractionation of antimosquito limonoids from Turraea abyssinica and Turraea cornucopia. J Biofertilizers Biopestic. 2014;5:1-5.

21. Innocent E, Joseph CC, Gikonyo NK, Nkunya MHH, Hassanali A. Growth disruption activity of polar extracts from Kotschyauguenensis (Fabaceae) against Anopheles gambiae s.s. (Diptera:Culicidae ) larvae. Int J Trop Insect Sci. 2008;28:220-4.

22. Seyoum A, Kabiru EW, Lwande W, Killeen GF, Hassanali A, Knols BGJ. Repellency of live potted plants against Anopheles gambiae from human baits in semi-field experimental huts. Am J Trop Med Hyg. 2002;67:191-5.

23. Das $S$, Garver L, Dimopoulos G. Protocol for mosquito rearing (A. gambiae). J Vis Exp. 2007;(5):221.

24. Ndo C, Kopya E, Menze-Djantio B, Toto JC, Awono-Ambene P, Lycett G, et al. High susceptibility of wild Anopheles funestus to infection with natural Plasmodium falciparum gametocytes using membrane feeding assays. Parasites Vectors. 2016;9:341.

25. Takken W, Smallegange RC, Vigneau AJ, Johnston V, Brown M, MordueLuntz AJ, et al. Larval nutrition differentially affects adult fitness and Plasmodium development in the malaria vectors Anopheles gambiae and Anopheles stephensi. Parasites Vectors. 2013;6:345

26. Pener MP, Dhadialla TS. An overview of insect growth disruptors; applied aspects. In: Dhadialla TS, editor. Insect growth disruptors. Cambridge: Academic Press; 2012. p. 1-162.

27. Andrews $S$. FastQC a quality control tool for high throughput sequence data. Babraham Bioinform. 2018:3-5.

28. Giraldo-Calderón Gl, Emrich SJ, MacCallum RM, Maslen G, Dialynas E, Topalis P, et al. VectorBase: an updated bioinformatics resource for invertebrate vectors and other organisms related with human diseases. Nucleic Acids Res. 2014;43:D707-13

29. Telleria EL, Benoit JB, Zhao X, Savage AF, Regmi S, e Silva TLA, et al. Insights into the trypanosome-host interactions revealed through transcriptomic analysis of parasitized tsetse fly salivary glands. PLoS Negl Trop Dis. 2014;8:e2649.

30. Mortazavi A, Williams BA, McCue K, Schaeffer L, Wold B. Mapping and quantifying mammalian transcriptomes by RNA-Seq. Nat Methods. 2008:5:621-8.

31. Baggerly KA, Deng L, Morris JS, Aldaz CM. Differential expression in SAGE: accounting for normal between-library variation. Bioinformatics. 2003:19:1477-83. 
32. Reimand J, ArakT, Adler P, Kolberg L, Reisberg S, Peterson H, et al. g:Profiler-a web server for functional interpretation of gene lists (2016 update). Nucleic Acids Res. 2016;44:W83-9.

33. Seaman JA, Alout H, Meyers Jl, Stenglein MD, Dabiré RK, Lozano-Fuentes $\mathrm{S}$, et al. Age and prior blood feeding of Anopheles gambiae influences their susceptibility and gene expression patterns to ivermectin-containing blood meals. BMC Genomics. 2015;16:797.

34. Fontoura NG, Bellinato DF, Valle D, Lima JBP. The efficacy of a chitin synthesis inhibitor against field populations of organophosphate-resistant Aedes aegypti in Brazil. Mem Inst Oswaldo Cruz. 2012;107:387-95.

35. Farnesi LC, Brito JM, Linss JG, Pelajo-Machado M, Valle D, Rezende GL. Physiological and morphological aspects of Aedes aegypti developing larvae: effects of the chitin synthesis inhibitor novaluron. PLoS ONE. 2012; 7:e30363.

36. Moussian B. Recent advances in understanding mechanisms of insect cuticle differentiation. Insect Biochem Mol Biol. 2010;40:363-75.

37. Altschul SF, Gish W, Miller W, Myers EW, Lipman DJ. Basic local alignment search tool. J Mol Biol. 1990;215:403-10.

38. Rebers JE, Willis JH. A conserved domain in arthropod cuticular proteins binds chitin. Insect Biochem Mol Biol. 2001;31:1083-93.

39. Ioannidou ZS, Theodoropoulou MC, Papandreou NC, Willis JH, Hamodrakas SJ. CutProtFam-Pred: detection and classification of putative structural cuticular proteins from sequence alone, based on profile hidden Markov models. Insect Biochem Mol Biol. 2014;52:51-9.

40. Willis JH. Structural cuticular proteins from arthropods: annotation, nomenclature, and sequence characteristics in the genomics era. Insect Biochem Mol Biol. 2010;40:189-204.

41. Salazar CE, Mills-hamm D, Kumar V, Collins FH. Sequence of a cDNA from the mosquito Anopheles gambiae encoding a homologue of human ribosomal protein S7. Nucleic Acids Res. 1993;21:4147.

42. Rozen S, Skaletsky H. Primer3 on the WWW for general users and for biologist programmers. In: Misener S, Krawetz SA, editors. Bioinformatics methods and protocol. New Jersey: Humana Press; 2000. p. 365-86.

43. Pfaffl MW, Tichopad A, Prgomet C, Neuvians TP. Determination of stable housekeeping genes, differentially regulated target genes and sample integrity: BestKeeper-Excel-based tool using pair-wise correlations. Biotechnol Lett. 2004;26:509-15.

44. Pfaffl MW. A new mathematical model for relative quantification in realtime RT-PCR. Nucleic Acids Res. 2001;29:45e-45.

45. Vyazunova I, Lan Q. Stage-specific expression of two actin genes in the yellow fever mosquito, Aedesaegypti. Insect Mol Biol. 2004;13:241-9.

46. Burmester T. Expression and evolution of hexamerins from the tobacco hornworm, Manduca sexta, and other Lepidoptera. Insect Biochem Mol Biol. 2015;62:226-34.

47. Korochkina SE, Gordadze AV, York JL, Beneš H. Mosquito hexamerins: characterization during larval development. Insect Mol Biol. 1997;6:11-21.

48. Telfer WH, Kunkel JG. The function and evolution of insect storage hexamers. Annu Rev Entomol. 1991;36:205-28.

49. Enderle U, Käuser G, Renn L, Scheller K, Koolman J. Ecdysteroids in the hemolymph of blowfly are bound to calliphorin. In: Scheller K, editor. The larval serum proteins of insects: function, biosynthesis, genetic. Stuttgart: Thieme; 1983. p. 40-9.

50. Braun RP, Wyatt GR. Sequence of the hexameric juvenile hormonebinding protein from the hemolymph of Locusta migratoria. J Biol Chem. 1996:271:31756-62

51. Rebers JE, Riddiford LM. Structure and expression of a Manduca sexta larval cuticle gene homologous to Drosophila cuticle genes. J Mol Biol. 1988;203:411-23.

52. Iconomidou VA, Willis JH, Hamodrakas SJ. Unique features of the structural model of "hard" cuticle proteins: implications for chitin-protein interactions and cross-linking in cuticle. Insect Biochem Mol Biol. 2005;35:553-60.

53. Huang Y, Guo Q, Sun X, Zhang C, Xu N, Xu Y, et al. Culex pipiens pallens cuticular protein CPLCG5 participates in pyrethroid resistance by forming a rigid matrix. Parasites Vectors. 2018;11:6.

54. Simma EA, Dermauw W, Balabanidou V, Snoeck S, Bryon A, Clark RM, et al. Genome-wide gene expression profiling reveals that cuticle alterations and P450 detoxification are associated with deltamethrin and DDT resistance in Anopheles arabiensis populations from Ethiopia. Pest Manag Sci. 2019;75:1808-18.
55. Yahouédo GA, Chandre F, Rossignol M, Ginibre C, Balabanidou V, Mendez NGA, et al. Contributions of cuticle permeability and enzyme detoxification to pyrethroid resistance in the major malaria vector Anopheles gambiae. Sci Rep. 2017;7:11091.

56. Jan S, Liu S, Hafeez M, Zhang X, Dawar FU, Guo J, et al. Isolation and functional identification of three cuticle protein genes during metamorphosis of the beet armyworm, Spodopteraexigua. Sci Rep. 2017;7:16061.

57. Zhang J, Lu A, Kong L, Zhang Q, Ling E. Functional analysis of insect molting fluid proteins on the protection and regulation of ecdysis. J Biol Chem. 2014;289:35891-906.

58. Huang X, Warren JT, Buchanan J, Gilbert LI, Scott MP. Drosophila Niemann-Pick Type C-2 genes control sterol homeostasis and steroid biosynthesis: a model of human neurodegenerative disease. Development. 2007;134:3733-42.

59. Niwa R, Niwa YS. Enzymes for ecdysteroid biosynthesis: their biological functions in insects and beyond. Biosci Biotechnol Biochem. 2014;78:1283-92.

60. Muramatsu D, Kinjoh T, Shinoda T, Hiruma K. The role of 20-hydroxyecdysone and juvenile hormone in pupal commitment of the epidermis of the silkworm, Bombyx mori. Mech Dev. 2008;125:411-20.

61. Pegg AE. Regulation of ornithine decarboxylase. J Biol Chem. 2006;281:14529-32.

62. Mandal C, Ghosh N, Dey N, Adak MK. Effects of putrescine on oxidative stress induced by hydrogen peroxide in Salvinia natans L. J Plant Interact. 2014;9:550-8.

63. Lan Q, Grier CA. Critical period for pupal commitment in the yellow fever mosquito, Aedesaegypti. J Insect Physiol. 2004;50:667-76.

64. Kamita SG, Samra Al, Liu JY, Cornel AJ, Hammock BD. Juvenile hormone $(\mathrm{JH})$ esterase of the mosquito Culex quinquefasciatus is not a target of the JH analog insecticide methoprene. PLOS ONE. 2011;6:e28392.

65. Riddiford LM. How does juvenile hormone control insect metamorphosis and reproduction? Gen Comp Endocrinol. 2012;179:477-84.

66. Smith CR, Morandin C, Noureddine M, Pant S. Conserved roles of Osiris genes in insect development, polymorphism and protection. J Evol Biol. 2018:31:516-29.

67. Epis S, Porretta D, Mastrantonio V, Comandatore F, Sassera D, Rossi P, et al. $A B C$ transporters are involved in defense against permethrin insecticide in the malaria vector Anopheles stephensi. Parasites Vectors. 2014;7:349.

68. Guzov VM, Unnithan GC, Chernogolov AA, Feyereisen R. CYP12A1, a mitochondrial cytochrome P450 from the house fly. Arch Biochem Biophys. 1998;359:231-40.

69. War AR, Sharma HC. Induced resistance in plants and counter-adaptation by insect pests. Short Views Insect Biochem Mol Biol. 2014;2:533-47.

70. Ranson H, Hemingway J. Mosquito glutathione transferases. In: Sies H, Packer L, editors. Methods in enzymology. Cambridge: Academic Press; 2005. p. 226-41.

71. Chen TH, Tang P, Yang CF, Kao LH, Lo YP, Chuang CK, et al. Antioxidant defense is one of the mechanisms by which mosquito cells survive dengue 2 viral infection. Virology. 2011:410:410-7.

72. Edwin ES, Vasantha-Srinivasan P, Senthil-Nathan S, Thanigaivel A, Ponsankar A, Pradeepa V, et al. Anti-dengue efficacy of bioactive andrographolide from Andrographis paniculata (Lamiales: Acanthaceae) against the primary dengue vector Aedes aegypti (Diptera: Culicidae). Acta Trop. 2016;163:167-78

73. Li B, Calvo E, Marinotti O, James AA, Paskewitz SM. Characterization of the c-type lysozyme gene family in Anopheles gambiae. Gene. 2005:360:131-9.

74. Gräf R, Lepier A, Harvey WR, Wieczorek H. A novel 14-kDa V-ATPase subunit in the tobacco hornworm midgut. J Biol Chem. 1994;269:3767-74.

75. Zhou Y, Badgett MJ, Billard L, Bowen JH, Orlando R, Willis JH. Properties of the cuticular proteins of Anopheles gambiae as revealed by serial extraction of adults. PLoS ONE. 2017;12:e0175423.

76. Sharma A, Anderson TD, Sharakhov IV. Toxicological assays for testing effects of an epigenetic drug on development, fecundity and survivorship of malaria mosquitoes. J Vis Exp. 2015;95:e52041.

\section{Publisher's Note}

Springer Nature remains neutral with regard to jurisdictional claims in published maps and institutional affiliations. 